\title{
Correction to: The evaluation of Rolimeter, KLT, KiRA and KT-1000 arthrometer in healthy individuals shows acceptable intra-rater but poor inter-rater reliability in the measurement of anterior tibial knee translation
}

\author{
Armin Runer ${ }^{1} \cdot$ Tommaso Roberti di Sarsina $^{2} \cdot$ Vasco Starke $^{3} \cdot$ Alessandra Iltchev $^{3} \cdot$ Gernot Felmet $^{4} \cdot$ Sepp Braun $^{5,6}$. \\ Christian Fink $^{5,6} \cdot$ Robert Csapo $^{6}$
}

Published online: 14 September 2021

(c) The Author(s) 2021

\section{Correction to: \\ Knee Surgery, Sports Traumatology, Arthroscopy \\ (2021) 29:2717-2726 \\ https://doi.org/10.1007/s00167-021-06540-9}

In the above-mentioned article there is an error stating that the Rolimeter (Aircast Europe) is no longer commercially available. This information is not correct. There are still ways to purchase the Rolimeter, including on the recently launched website www.rolimeter.com.

Open access This article is licensed under a Creative Commons Attribution 4.0 International License, which permits use, sharing, adaptation, distribution and reproduction in any medium or format, as long as you give appropriate credit to the original author(s) and the source, provide a link to the Creative Commons licence, and indicate if changes were made. The images or other third party material in this article are included in the article's Creative Commons licence, unless indicated otherwise in a credit line to the material. If material is not

The original article can be found online at https://doi.org/10.1007/ s00167-021-06540-9.

Armin Runer

armin.runer@i-med.ac.at

1 Department of Orthopaedics and Traumatology, Medical University of Innsbruck, Innsbruck, Austria

2 Clinica Ortopedica e Traumatologica, Istituto Ortopedico Rizzoli, Bologna, Italy

3 Medical University of Innsbruck, Innsbruck, Austria

4 Orthopädische Praxis and ARTICO Sportklinik, Schwenningen, Germany

5 Gelenkpunkt - Sports and Joint Surgery, Innsbruck, Austria

6 Medical Informatics and Technology, ISAG, Research Unit for Orthopaedic Sports Medicine and Injury Prevention, Private University for Health Sciences, Innsbruck, Austria included in the article's Creative Commons licence and your intended use is not permitted by statutory regulation or exceeds the permitted use, you will need to obtain permission directly from the copyright holder. To view a copy of this licence, visit http://creativecommons. org/licenses/by/4.0/.

Publisher's Note Springer Nature remains neutral with regard to jurisdictional claims in published maps and institutional affiliations. 